\title{
Using an Adaptive Network-based Fuzzy Inference System to Estimate the Vertical Force in Single Point Incremental Forming
}

\author{
S.G. Racz, R.E. Breaz, O. Bologa, M. Tera, V.S. Oleksik
}

\author{
Sever-Gabriel Racz, Radu-Eugen Breaz*, Octavian Bologa, \\ Melania Tera, Valentin-Stefan Oleksik \\ Department of Industrial Machines and Equipment \\ Lucian Blaga University of Sibiu, Romania, 550024 Sibiu, Victoriei, 10, Romania \\ gabriel.racz@ulbsibiu.ro \\ *Corresponding author: radu.breaz@ulbsibiu.ro \\ octavian.bologa@ulbsibiu.ro, \\ melania.tera@ulbsibiu.ro, valentin.oleksik@ulbsibiu.ro
}

\begin{abstract}
Manufacturing processes are usually complex ones, involving a significant number of parameters. Unconventional manufacturing processes, such as incremental forming is even more complex, and the establishment of some analytical relationships between parameters is difficult, largely due to the nonlinearities in the process. To overcome this drawback, artificial intelligence techniques were used to build empirical models from experimental data sets acquired from the manufacturing processes. The approach proposed in this work used an adaptive network-based fuzzy inference system to extract the value of technological force on Z-axis, which appears during incremental forming, considering a set of technological parameters (diameter of the tool, feed and incremental step) as inputs. Sets of experimental data were generated and processed by means of the proposed system, to make use of the learning ability of it to extract the empirical values of the technological force from rough data.
\end{abstract}

Keywords: adaptive network-based fuzzy inference system, CNC milling machines, incremental forming, technological force.

\section{Introduction}

Manufacturing processes are usually involving a significant number of parameters. Complex analytical models were developed to express the dependencies between these parameters, for every manufacturing processes, but the complexity of the factors involved in these processes often affect the utility and accuracy of such models.

To compensate this drawback, methods involving artificial intelligence techniques, such as fuzzy logic, artificial neural networks, adaptive network-based fuzzy inference systems and adaptive neuro fuzzy inference systems were used to extract significant information, such as empirical relationships between parameters, form large amount of manufacturing processes rough data, where analytical dependencies between inputs and outputs were difficult to be derived. These methods make use of the learning ability of the artificial intelligence systems to overcome the complexity of the phenomenon involved in machining processes.

A synthesis regarding the main ideas and activities or the renowned scientist Lofti Zadeh, the father of fuzzy logic was presented in [8]. Among others, fuzzy data processing was pointed as a very useful application of fuzzy logic. A comprehensive presentation regarding the fuzzification of classical structures was introduced in the survey work [9], which can be used as starting theoretical support for every research using fuzzy logic methods and tools. Fuzzy linguistic modeling was the subject of the review presented in [12], which stated the fact that fuzzy linguistic modeling has proven as a useful tool for information accessing systems. 
As presented above, fuzzy logic has numerous useful applications, industrial control being one of the most important ones. A survey paper synthesizing the industrial applications of fuzzy control was introduced in [21]. Another work regarding modeling and simulation of a combined PID-fuzzy control structure for a telerobot was introduced in [11].

The work presented in [25] used fuzzy logic to predict the surface roughness in milling processes. A fuzzy inference system using cutting regime parameters (such as cutting speed, and feed per tooth, cutting forces values), parameters linked with the tool geometry (tool nose radius) and parameters related to the cutting conditions (the use of cutting fluids) as inputs was designed. The system was able to calculate the surface roughness as an output, in an empirical way. Experimental work unfolded during this research had shown that the data predicted by the fuzzy system were close to the experimental ones.

The development of a system based upon fuzzy adaptive networks to overcome the complexity introduced by high-speed machining in turning operations was introduced in [15]. A model based upon fuzzy adaptive networks was built and used to predict surface roughness in turning. Experimental data was used to validate the proposed model.

The researches presented in [16] proposed the use of adaptive neuro-fuzzy inference systems to predict the surface quality obtained by means of end milling. Four parameters (feed, speed, vibration and depth of cut) were used as inputs, while the considered output parameter was roughness. The experimental data set was used for both training and validation for the proposed technique. The approach was found to be superior to the use of artificial neural networks from the point of view of prediction accuracy. The authors considered adaptive neuro-fuzzy inference systems as hybrid intelligent techniques, while the use of artificial neural networks was considered a simple intelligent one.

In [4] the research team developed an adaptive neuro-fuzzy inference systems model to predict the white layer thickness and surface roughness for an electro discharge machining process. Some process parameters such as duration of the pulse, feed rate of the wire, open circuit voltage and dielectric pressure were used as inputs for the adaptive neuro fuzzy inference systems system. Experimental data was used for validating the approach, which was found to provide feasible results.

The work presented in [25] compared the use of adaptive neuro fuzzy inference systems and backpropagation artificial neural networks to predict the values of some specific process parameters (roughness, tool wear and metal removal rate) for an electro discharge machining process. The above-mentioned parameters were used as outputs, while capacitance, feed rate, gap voltage and threshold were considered as inputs. The results had also shown that adaptive neuro-fuzzy inference systems outperformed artificial neural networks for the prediction task.

The fusion of a support vector machine with adaptive neuro-fuzzy inference systems for fault detection of an industrial system was introduced in [22]. A simulation study had proven that the fusion-based approach performed better than individual support vector machine and adaptive neuro fuzzy inference systems.

Artificial intelligence techniques, mainly their ability to cope with experimental sets of data and extract and/or predict crisp empirical values for significant output parameters were also used in [19], were an air pollution forecasting system based upon artificial neural networks was designed and tested. Robot control is another filed of application of such computational intelligence methods. The work from [6] used reduced training examples for artificial neural networks to control a robot with six degrees of freedom. 


\section{Single point incremental forming - technological forces}

Single point incremental forming (SPIF) is an unconventional forming process which allows the user to manufacture prototypes or small batches of sheet metal parts by combining three or more technological movements in a flexible manner [14] [18] [10] [2].

A brief description of the SPIF process principle is depicted in (Fig. 1). The blank (2) is fixed by means of the blank holder (3). In order to realize the shape of the sheet metal part, one of the active elements, usually the punch (1) has an axial feed vertical movement direction, continuous or incremental (with the step s), while the other element, the active plate (4) carries out a plane horizontal movement.

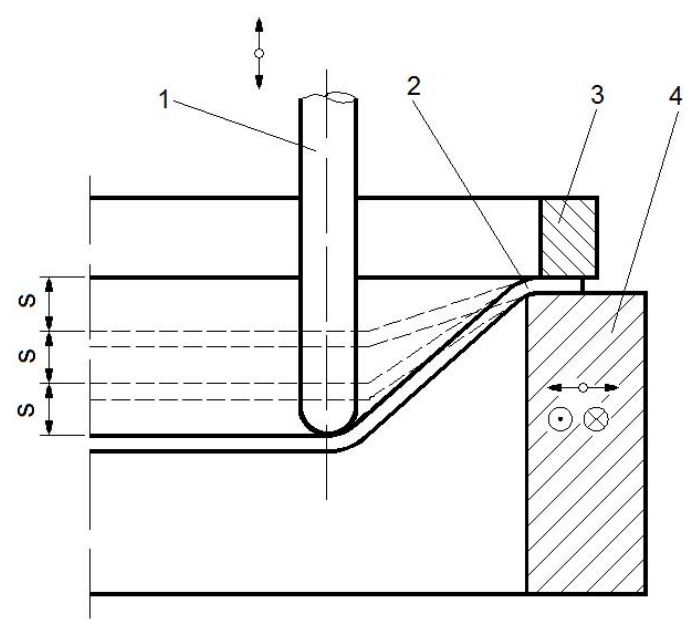

Figure 1: Single point incremental forming - principle

The SPIF process still has many drawbacks, which hinder its industrial implementation. One of them is related with the lack of specific technological equipment. Prototype machines are used in research facilities for unfolding the process. A literature survey has reported also CNC milling machines and serial industrial robots [5], [23] as technological equipment used for the process, with a special emphasis, by the usage point of view, on CNC milling machines. Consequently, it may be stated that the process is unfolded most frequently on CNC milling machines, which are sensitive and expensive equipment.

Another drawback of the process is related to the difficulty of estimating the technological forces, which became very important when CNC milling machines are involved. Forces exceeding the allowable values on each kinematic chain could appear and damage the CNC machine. Some modern CNC working centers are equipped with electronic safety systems, which can stop the movements on all axes when the resistant forces and torques are surpassing the allowable values, but this is not a general situation. There are CNC machines which are not fitted with such systems, or these systems could be too slow to stop the process before damages occur. The user must take into consideration both scenarios (best and worst case) and, of course try to avoid the risk of damaging the machine. It is here noticeable that even if the safety systems intervene and stops the process, productivity will be affected (Fig. 2).

A lot of researches were conducted recently to develop some methods of calculating and assessing the technological forces within the SPIF process, not only for avoiding machine damage, but also because accurate information about the values of the technological forces are also important to predict the plastic behavior of the sheet metal part.

In [7] the influence of the tool diameter, vertical depth increment and steepness of the part's wall or wall angle is studied, by manufacturing a simple geometry part, a cone. The result shows 


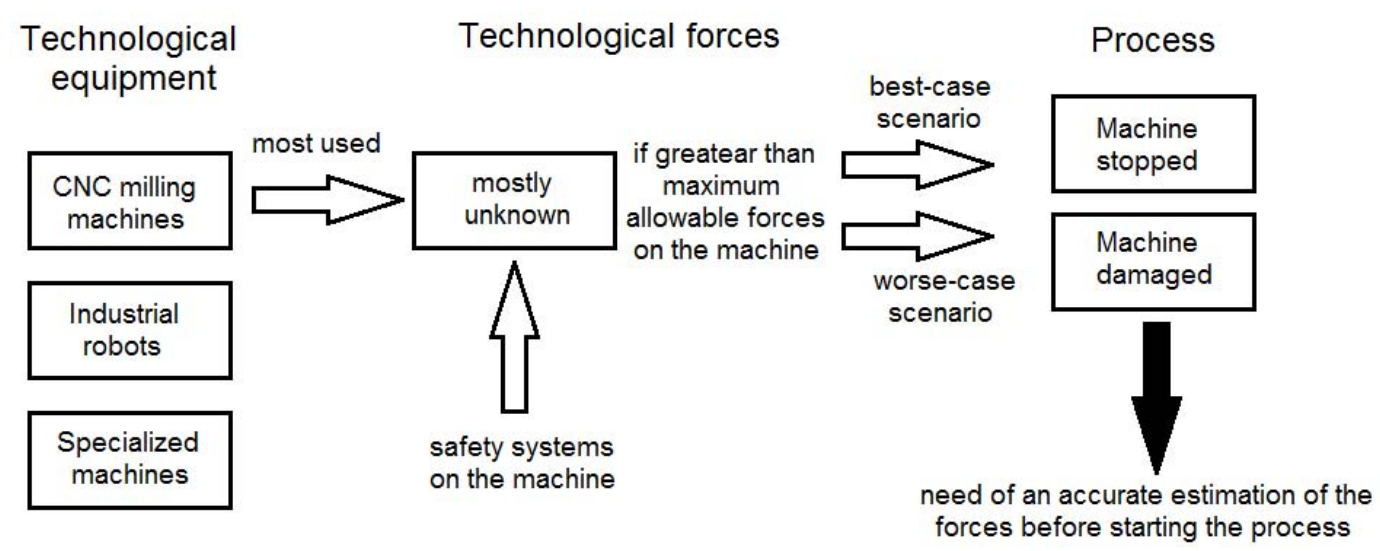

Figure 2: Flowchart of the influence of unknown technological forces upon the CNC milling machines

that if the vertical step size, tool diameter or wall angle are increased the forces will increase as well.

The research presented in [1] was focused on establishing practical formulae enabling the calculation of forces occurring during the single point incremental forming process, based on experimental results as well as analytical relations derived from finite element analysis (FEA) results. The experiments were unfolded for manufacturing a conical part. The formula for the vertical force takes into consideration the characteristics of the material (tensile strength), the material thickness, the diameter of the tool, the vertical step (expressed by the influence of it on the scallop height) and the wall angle of the conical part.

Another approach, presented in [17], was focused on experimental measurement on forming forces in the conical frustum-forming process to analyze the trend of forming force. Finally, analytical models for tangential force prediction were proposed and validated through experimental data. An empirical combined model has been constructed which could provide the prediction of tangential force with an average error less than $11 \%$ for the experimental conditions employed in the experimental research.

The work presented in [20] compared the formulae developed in [1] with experimental results. It was verified that the proposed analytical formula has been adequate for constant wall angle slopes but limited to predict the forming force of variable wall angle geometries.

In [26], a discussion regarding the process parameters upon the technological forces is presented, based upon a synthesis of the results presented in the literature. According to that, the main parameters which influence the behavior of the forces are:

- Tool diameter (proportional influence, an increase in the tool diameter leads to an increase in the force value);

- Vertical step size (proportional influence);

- Sheet thickness (proportional influence);

- Wall angle slope (proportional influence).

It is noticeable the fact that the influence of these parameters (mainly the wall angle slope was synthesized and reported for different shapes of the parts (cone, conical frustum and pyramid) and for different materials (steel and aluminum alloys). 
Most of the researches reported that the experimental measurements of the technological forces employed specialized devices, such as 3D dynamometers or custom designed data acquisition systems, which are very expensive and nod widely available. The latest mentioned systems also take a long time for setting-up and calibration.

Some previous work of the authors of this paper was presented in [24]. A reduced experimental data set was used in that approach and only two parameters were considered as input for the adaptive network-based fuzzy inference system (feed in the horizontal plane and depth). It was considered that only two parameters are not enough to describe the evolution of the vertical technological force. The approach presented here significantly developed the preliminary adaptive network-based fuzzy inference system presented in [24], by using more parameters within the SPIF process as inputs and significantly extending the amount of data processed by the system (268 data sets instead of 90 data sets).

In this paper, the authors set forth a method for measuring the technological forces which can be used even at workshops level and involves no supplementary costs, out of the initial costs of the CNC milling machine. Also, using a neuro-fuzzy approach, the experimentally gathered database was organized as a technological knowledge base, which allow the user to assess the value of the vertical technological force outside the process (table 4).

Table 1: Process parameters

\begin{tabular}{|c|c|c|}
\hline $\begin{array}{l}\text { Process parameters } \\
\text { considered in the } \\
\text { literature }\end{array}$ & $\begin{array}{l}\text { Process parameters } \\
\text { considered in the } \\
\text { proposed approach }\end{array}$ & Observations \\
\hline Tool diameter & Tool diameter & \\
\hline Vertical step size & Vertical step size & \\
\hline Sheet thickness & - & $\begin{array}{l}\text { The approach was to develop knowledge } \\
\text { databases for every sheet thickness } \\
\text { of a given material, so sheet thickness } \\
\text { was not considered as an input variable }\end{array}$ \\
\hline Wall angle slope & - & $\begin{array}{l}\text { The influence of the wall angle slope could } \\
\text { not be predicted by analytical approaches } \\
\text { [20]. Moreover, industrial implementation } \\
\text { of the process involves manufacturing } \\
\text { parts with highly variable wall angle slope }\end{array}$ \\
\hline- & Feed & \\
\hline- & Spindle speed & Considered only during initial approach \\
\hline
\end{tabular}

The proposed approach indicates as influence factors for the value of the vertical technological force, in the initial phase, the tool diameter, the vertical step size, the feed and the spindle speed. In order to preserve the degree of generality, no particular geometry of the processed part was taken into consideration (cone, conical frustum or pyramids), so no wall angles were considered as influence factors in this stage of the researches.

\section{Method for calculating the vertical technological force}

The technological movements required by the SPIF process are performed on CNC milling machine tools by means of the feed drives. The typical structure of a linear feed drive, either horizontal or vertical consists of a rotary servomotor axially coupled with a ball screw system. The schematic diagrams of a horizontal and a vertical feed drives are presented in (Fig. 3 a and 
b).

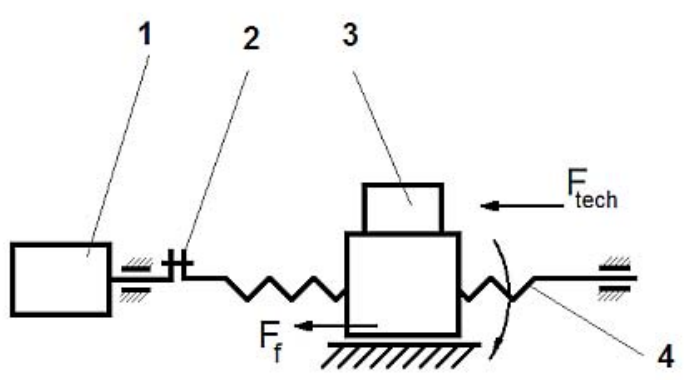

a.

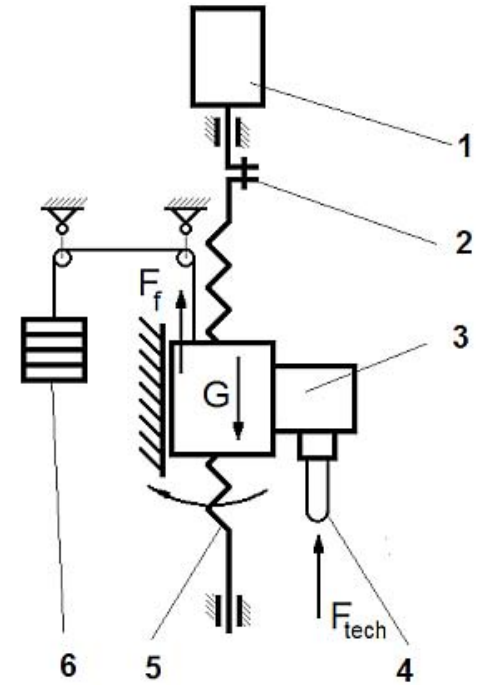

b.

Figure 3: Schematic loads diagram for a horizontal (a) and a vertical (b) feed drive

The notations from (Fig. 3 a) have the following significations: 1 - drive motor, 2 - axial coupling, 3 - horizontal slide and part, 4 - lead ball-screw.

The notations from (Fig. 3 b) have the following significations: 1 - drive motor, 2 - axial coupling, 3 - vertical slide and working unit (with the main spindle), 4 - tool, 5 - lead ball-screw, 6 - counterweight for balancing the weight of the working unit.

The drive motor of a CNC feed drive must overcome both the static and the dynamic torques which appear during the machining process:

$$
T_{m o t}=T_{s t}+T_{d i n}
$$

where:

$T_{\text {mot }}$ - motor torque;

$T_{s t}$ - resistant static torque;

$T_{d}$ - resistant dynamic torque.

The total static torque for a horizontal feed drive may be calculated with the following relation:

$$
T_{s t}=\frac{\left(F_{t e c h}+F_{f}\right) p}{2 \pi \eta_{t o t}}
$$

where:

$F_{\text {tech }}$ - resistant technological force $[\mathrm{N}]$;

$F_{f}$ - friction force;

$\mathrm{p}$ - ball-screw step [mm];

i - transfer ratio between motor and ball screw;

$\eta_{t o t}$ - total mechanical efficiency.

For the considered CNC milling machine-tool the value of step is $\mathrm{p}=4.233 \mathrm{~mm}$ When vertical feed drives are considered, the friction force opposes the weight force of the machine slide $(G)$, consequently, relation (2) must be rewritten as: 


$$
T_{s t}=\frac{\left(F_{t e c h}-G+F_{f}\right) p}{2 \pi \eta_{t o t}}
$$

where only the down movement has been taken into consideration (the technological force appears only when the tool is driven down, towards the workpiece).

A 3-axis (X, Y, Z) Haas CNC Mini Mill was used as technological equipment. On each axis, the actuating motor is directly coupled with the ball screw, so the transfer ratio $i=1$. According to this, the resistant static torque on Z-axis (vertical direction) may be expressed as:

$$
T_{s t}=\frac{\left(F_{t e c h}-G+F_{f Z}\right) p}{2 \pi \eta_{t o t}}
$$

The CNC equipment displays at the level of operator panel the current value of the motor torque, for each axis, as a percent value. The percent value is linked with a certain crisp value of the motor torque, which is different from both nominal and maximal values. If the readings are done during the constant velocity phase, the dynamic torque (4) may be considered zero and consequently neglected.

To calculate the amount of the motor torque which is considered as $100 \%$, the values of the static torque in the no-load conditions were subtracted from the values in load conditions, according to the following relations:

$$
\Delta T_{s t}=\frac{\left(F_{t e c h}-G+F_{f Z}\right) p}{2 \pi \eta_{t o t}}-\frac{\left(-G+F_{f Z}\right) p}{2 \pi \eta_{t o t}}=\frac{F_{t e c h Z} \cdot p}{2 \pi \eta_{t o t}}
$$

where:

$\Delta T_{s t Z}$ - difference between static torque in load and no-load conditions on Z-axis.

Expressing the left-hand side of equation (5) based on the maximum feed force allowed on Z-axis (8896 N, taken from the machine documentation) leads to:

$$
\Delta T_{\text {max_st }}=\frac{F_{\text {tech } Z} \cdot p}{2 \pi \eta_{\text {tot }}}=\frac{8896 \cdot 4.233 \cdot 10^{-3}}{2 \cdot 3.14 \cdot 0.9}=6.65[\mathrm{Nm}]
$$

where:

$\Delta T_{\text {max }}$ st $Z$ - the maximum difference between static torque in load and no-load conditions on Z-axis.

The efficiency factor for the screw nut assembly was considered $\eta=0.9$. It can be observed that the values of $\Delta T_{\text {max }_{-} s t Z}$ is in-between the values of the nominal torque $\left(T_{n}=5.39 \mathrm{Nm}\right)$ and maximum torque $\left(T_{\max }^{-}=13.8 \mathrm{Nm}\right)$ of motors.

Considering $\Delta t_{Z}$ the difference between the load and no-load static torques read from the operator panel of the machine (in percent), the following relation may be written:

$$
\Delta T_{s t Z}=\frac{\Delta T_{\text {max_st } Z} \cdot \Delta t_{Z}}{100}
$$

Equation (7) allows now the user to calculate of the vertical technological force, by using the difference between the values of the torques, displayed by the CNC equipment. The percent displayed values of torques can be replaced by crisp numerical values, knowing the $100 \%$ reported motor torque calculated by means of equations (6) and (7). The technological forces can now be calculated using the relation:

$$
F_{t e c h Z}=\frac{2 \pi \eta_{t o t}}{p} \Delta T_{s t Z}=\frac{2 \pi \eta_{t o t}}{p} \cdot \frac{\Delta T_{\text {max _st } Z} \cdot \Delta t_{Z}}{100}
$$


For a given movement cycle, it is only necessary to program the same cycle in no-load conditions, prior to unfolding it in load conditions, to be able to read and subtract the no-load and load-conditions torques.

To validate the proposed calculation method, the technological force on Z-axis was measured using a data acquisition system. The differences between measured and calculated values were found to be in the range of $1 \%$ resolution of the CNC operator panel display, leading to a maximum error of $88.6 \mathrm{~N}$. Considering that for incremental forming of steel sheets the vertical technological force could reach values greater than $2000 \mathrm{~N}$, this error was considered acceptable.

\section{Generating the experimental database}

An experimental program was unfolded to gather the data which will be processed by the adaptive network-based fuzzy inference system. The DC04 steel, with a thickness of 0.7 millimeters was used as workpieces material. Simple toolpaths were programmed (Fig. 4), and the punch was moved along them. On each component of the toolpath (segments from 1 to 10, each one with an overall length of 10 millimeters) the manufacturing inputs were modified. The inputs taken into consideration were tool diameter, spindle speed, feed on horizontal plane, incremental vertical step.

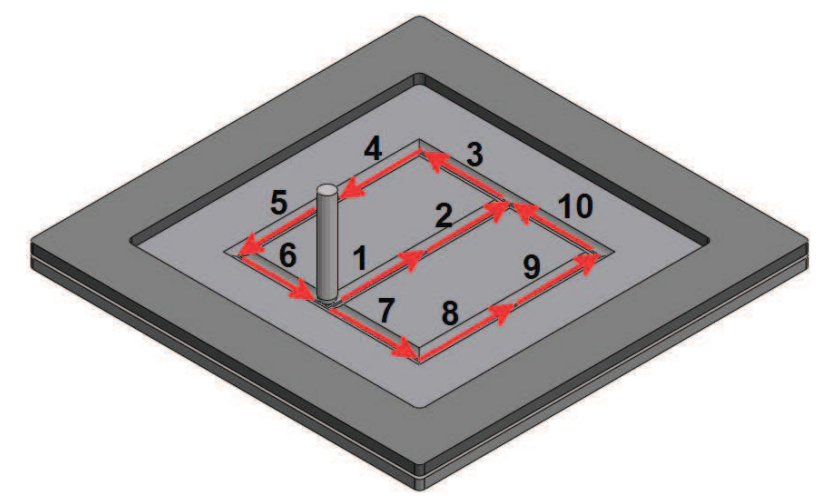

Figure 4: Toolpaths used for generating the experimental database

Some examples of the processed parts are presented in (Fig. 5).
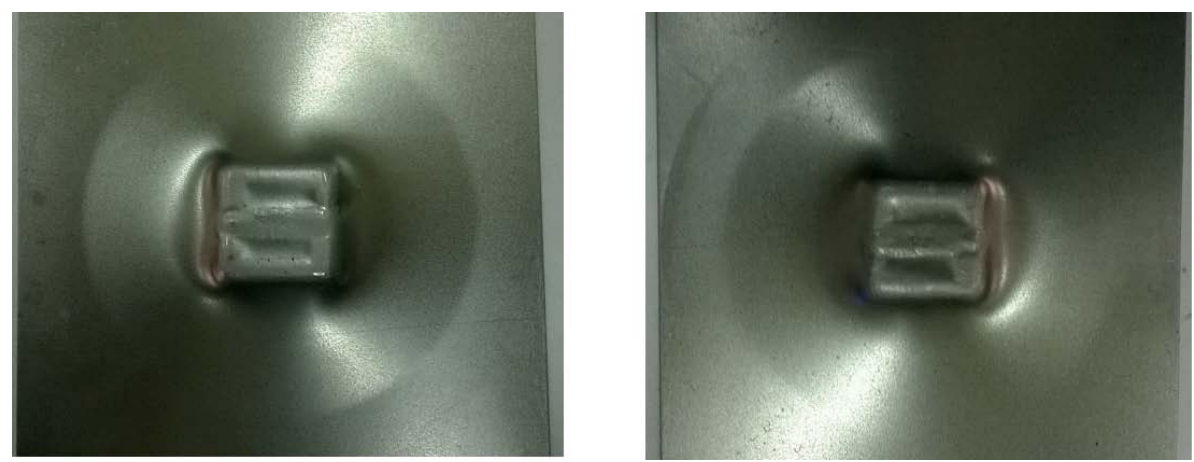

Figure 5: Examples of processed parts

As presented in equation (1), the dynamic resistant dynamic torque also appears during the acceleration and deceleration phases of the movement. To avoid its influence, the data form the 
operator panel was read in the constant velocity phase of the movements, when due to zero value of the linear and angular acceleration, the dynamic torque is also zero (Fig. 6). Every toolpath was generated in no-load and load conditions and the no-load values were subtracted form the first ones.

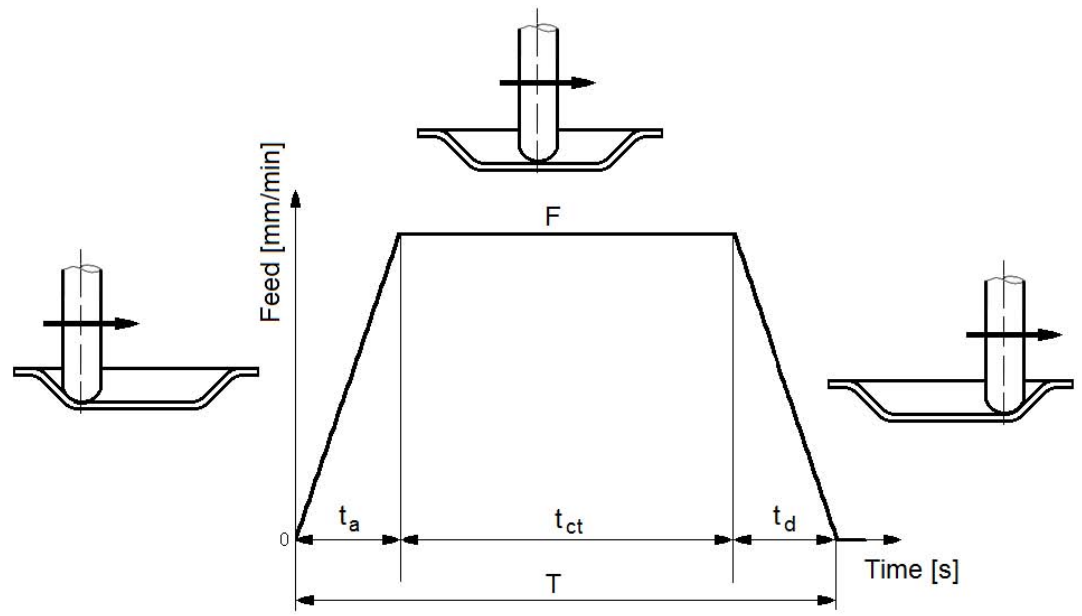

Figure 6: The readings from the operator panel were made after reaching the constant velocity on the axis

The data form the operator panel of the CNC equipment were captured by a digital camera and afterwards the needed information was extracted and processed. The image processing method used in this approach was described in detail in [3].

After this process, the $\Delta t_{Z}$ values were obtained and using equation (8) the vertical technological forces could be calculated.

For generating the rough data to be processed by the proposed adaptive network-based fuzzy inference system, a total of 268 experimental data sets were obtained by experimental tests. A reduced selection of these data is presented in (table 1 ).

Table 2: Example of experimental data set (selection)

\begin{tabular}{|c|c|c|c|c|}
\hline $\begin{array}{c}\text { Tool } \\
\text { diameter } \\
{[\mathbf{m m}]}\end{array}$ & $\begin{array}{c}\text { Spindle } \\
\text { speed } \\
{[\mathbf{r e v} / \mathbf{m i n}]}\end{array}$ & $\begin{array}{c}\text { Feed on } \\
\text { horizontal } \\
\text { plane } \\
{[\mathbf{m m} / \mathbf{m i n}]}\end{array}$ & $\begin{array}{c}\text { Vertical } \\
\text { step } \\
{[\mathbf{m m}]}\end{array}$ & $\begin{array}{c}\text { Technological } \\
\text { force } \\
{[\mathbf{N}]}\end{array}$ \\
\hline 8 & 400 & 200 & -1 & 1790.161 \\
\hline 8 & 360 & 130 & -2 & 1716.338 \\
\hline 8 & 450 & 175 & -2 & 1492.168 \\
\hline 10 & 300 & 50 & -1 & 977.211 \\
\hline 10 & 480 & 200 & -2 & 2043.60 \\
\hline 10 & 450 & 90 & -2 & 1066.049 \\
\hline 12 & 110 & 290 & -3 & 1425.840 \\
\hline 12 & 120 & 350 & -2.5 & 2186.288 \\
\hline 12 & 400 & 350 & -2.5 & 1901.120 \\
\hline & & & & \\
\end{tabular}

For each group of parameters from table two variation intervals were stated. The values for the tool diameter were set to only three values: 8,10 and $12 \mathrm{~mm}$. For the spindle speed, the limits were set between 0 and $500 \mathrm{~mm} / \mathrm{min}$ while for the feed on horizontal plane the limits were 
set between 50 and $350 \mathrm{~mm} / \mathrm{min}$. For the vertical step increments of 1, 2, 2.5 and $3 \mathrm{~mm}$ were used. The vertical step was increased using the above-mentioned increments up to a total depth of $7.5 \mathrm{~mm}$.

\section{Adaptive network-based fuzzy inference system}

The first stage of building the adaptive network-based fuzzy inference system model involved a selection process in order to find the most influential combination of input parameters upon the output parameter. As stated before, the data sets have taken into consideration four parameters as inputs (tool diameter, spindle speed, feed on horizontal plane, vertical step) and one parameter as output (technological force).

It was considered that a system with four inputs could be to complex and consequently a method of selecting only three inputs (the optimal ones) was considered. To fulfill this goal, the Matlab exhsrch command (from Fuzzy Logic Toolbox) was used. The function exhsrch performs an exhaustive search within the available inputs to select the set of inputs that most influence the output. Essentially, exhsrch builds an adaptive network-based fuzzy inference model for each combination and trains it for one epoch and reports the performance achieved. The results from exhsrch (Fig. 7) indicate that "Diameter", "Feed" and "Step" form the best combination of three input attributes. The training (continuous line with circle markers) and checking errors (dotted line with asterisks markers) are getting distinguished, indicating the outset of overfitting. The left-most input set of variables in (Fig. 7) has the least error or in other words the most relevance with respect to the output.

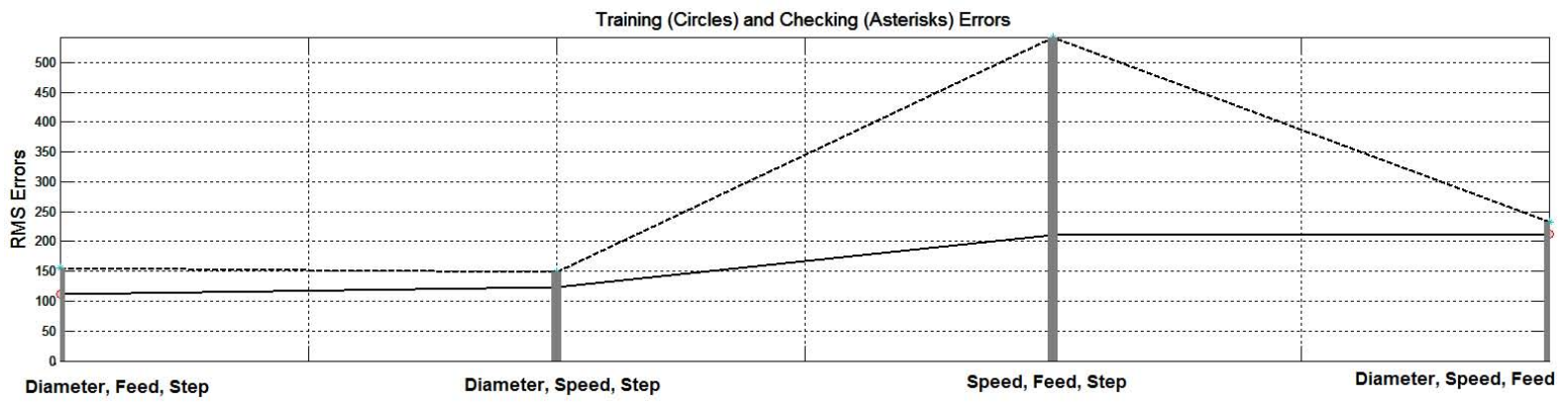

Figure 7: Tool diameter, vertical feed and incremental step - the optimal combination of three inputs

These results are in accordance with the literature survey, which in most of the cases considered speed as the least influential factor within the SPIF process. Most of the authors consider that a nonzero speed of the punch is only required as a measure to reduce friction and it only influences the overall roughness of the surface.

With the selection of input parameters done, the adaptive network-based fuzzy inference system was designed to calculate the vertical technological force, considered as an output.

As for any adaptive network-based fuzzy inference system, a training and checking process had to be unfolded. The experimental data sets were divided into training and checking sets. The division was made by selecting the odd values from the 268 experimental data set as training set while the even values were selected as checking set. At the beginning of the training process, a preliminary fuzzy inference system was generated. At this initial stage the fuzzy system does not reflect entirely the behavior of the considered system. During the training process, artificial neural networks were used to improve the fuzzy system, by means of a learning process. The learning process was completed after 3 stages (epochs), needed for the modelling errors to reach 
acceptable values. At the end of the learning process, the fuzzy inference system can accurately reflect the real relationships between inputs and output, for the entire range of variations.

The adaptive network-based fuzzy inference system was built and trained using the interactive graphical user interfaces provided by Matlab software packages and its modules, Fuzzy Logic and Neural Network toolboxes. The structure of the fuzzy inference system is presented in (Fig. 8). Triangular membership functions, presented in (Fig. 9) for the "feed" input, were selected. Figure 9 also presents the intervals of variation for the selected input.

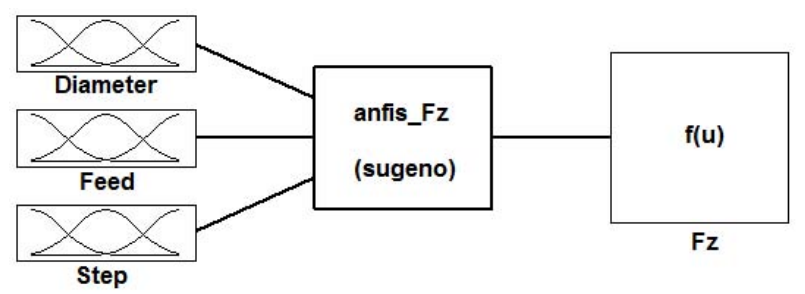

Figure 8: Structure of the fuzzy system

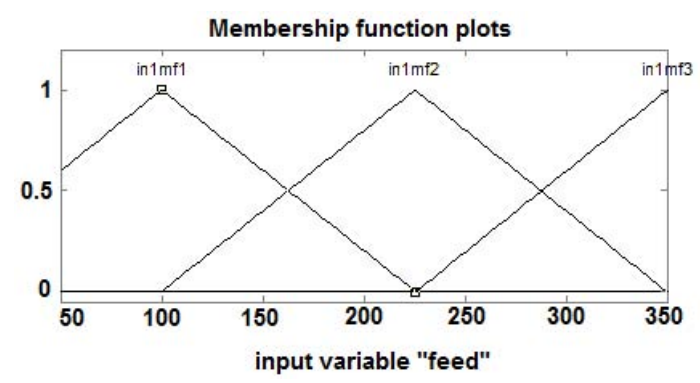

Figure 9: Membership function for the input variable "feed"

The final structure of the proposed system, presented in (Fig. 10) has three inputs, an output, 5 levels of ANN, 193 neurons and 81 fuzzy rules.

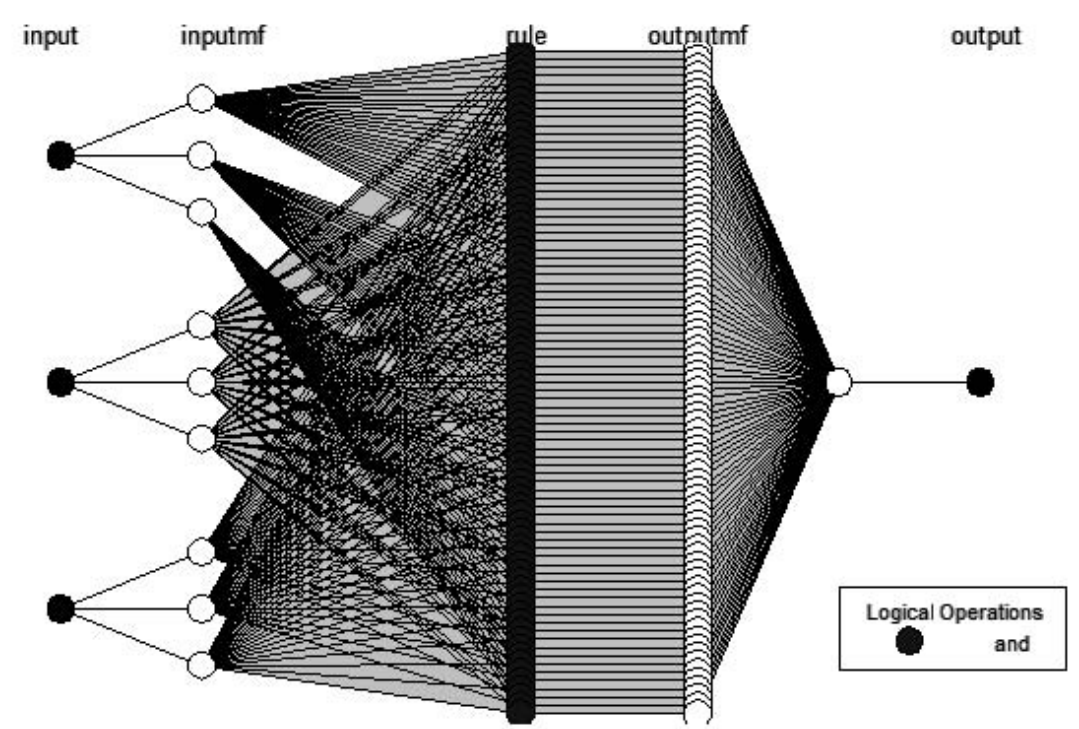

Figure 10: The structure of the neural networks for the proposed system

The adaptive network-based fuzzy inference system has an interactive graphical user interface, 
presented in (Fig. 1), which allows the user to calculate the output (vertical force) for any intermediary value from the inputs variation ranges. Thus, the system can predict the result for data which were not experimentally available. The user can either drag the vertical bars through any values of the two input variables, or manually introduce input data for them and the model will automatically calculate the value of the output (technological vertical force).
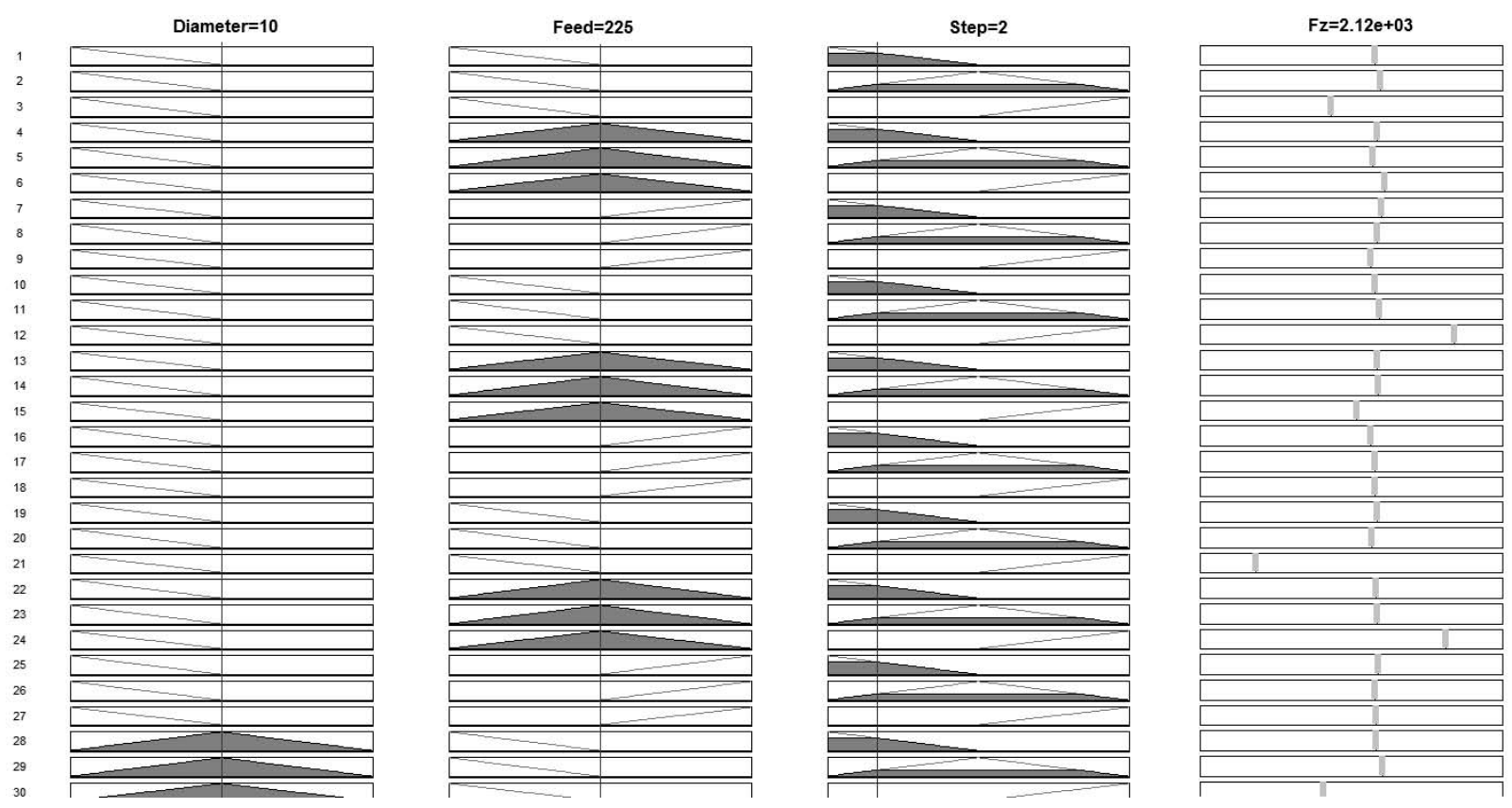

Figure 11: Graphical user interface of the adaptive network-based fuzzy inference system (only first 31 rules are visible in the figure, out of 81 )

No related fuzzy models were found in the literature for calculating the vertical technological force during SPIF. To evaluate the efficiency of the proposed model, a comparison between it and a linear regression model was unfolded. The comparison was made by comparing the RMSE (Root mean square) values against checking data for both models. For the proposed model the RMSE was 153.353, while for the linear regression model the RMSE error was 159.290. This result proves to a certain extent the usefulness of the proposed model. However, it should be stressed the fact that further experimental tests must be performed to validate the proposed model for different sheet thicknesses and different materials.

The experimental data (both training and checking data sets) and the adaptive networkbased fuzzy inference system (.fis file to be run using the graphical user interface ANFIS from Matlab) can be downloaded from the following link:

https://www.dropbox.com/s/s0gdpjap2istku5/anfis.zip?dl=0

\section{Conclusion}

The approach presented in this paper did not aim to develop an analytical expression for calculating the vertical force values, but to develop an adaptive network-based fuzzy inference system which allows the user to estimate in an empirical way the force for a given set of process parameters and their variation intervals.

Numerical simulation, using finite elements analysis is today able to calculate the forces within the SPIF process and this allows to evaluate if the process is safe or not for the technological 
equipment. However, numerical simulation requires both very expensive software packages and highly qualified personnel, able to develop and work with complex and accurate FEA models of the incremental forming process and run the above-mentioned simulations.

The approach presented in this paper offers a cost-effective alternative to that, the method requiring some simple experiments and a cost-effective software package. Moreover, the building of the network-based fuzzy system is a straightforward process, based only upon Matlab integrated graphical user interfaces and does not require a highly trained user.

The proposed method is dedicated to speed the adoption of the SPIF process by the industry, by offering a simple, yet (considered by authors) effective method for estimating the forces, which can be applied at workshops level, rather than in research laboratories.

Future researches will be oriented of taking into consideration different sheet thicknesses and different materials, besides the already considered parameters, to build a more comprehensive knowledge base.

\section{Funding}

This research was partially funded by the Romanian Ministry of Research and Innovation CCCDI-UEFISCDI, project number PN-III-P1-1.2-PCCDI-2017-0446/nr. 82PCCDI/2018, within PNCDI III, project title: "Smart Manufacturing Technologies for Advanced Production of Parts from Automotive and Aeronautics Industries".

\section{Author contributions}

The authors contributed equally to this work.

\section{Conflict of interest}

The authors declare no conflict of interest.

\section{Bibliography}

[1] Aerens, R.; Eyckens, P.; Van Bael, A.; Duflou, J. R. (2010); Force prediction for single point incremental forming deduced from experimental and FEM observations, International Journal of Advanced Manufacturing Technology, 46(9-12), 969-982, 2010.

[2] Behera, A.K.; De Sousa R.A.; Ingarao, G.; Oleksik, V. (2017); Single point incremental forming: An assessment of the progress and technology trends from 2005 to 2015, Journal of Manufacturing Processes, 27, 37-62, 2017.

[3] Breaz, R.; Bologa, O.; Tera, M.; Racz, G. (2013); Determination of Technological Forces in the Incremental Forming Process, Applied Mechanics and Materials, 371, 133-137, 2013.

[4] Caydas, U.; Hascalik, A.; Ekici, S. (2009); An adaptive neuro-fuzzy inference system (ANFIS) model for wire-EDM, Expert Systems with Applications, 36, 6135-6139, 2009.

[5] Ceretti, E.; Giardini, C.; Attanasio, A. (2004); Experimental and simulative results in sheet incremental forming on CNC machines, Journal of Materials Processing Technology, 152(2), 176-184, 2004. 
[6] Ciupan, E.; Lungu, F.; Ciupan, C. (2015); ANN Training Method with a Small Number of Examples Used for Robots Control, International Journal of Computers Communications E Control, 10(5), 643-653, 2015.

[7] Duflou, J. R.; Szekeres, A.; Vanherck, P. (2005); Force Measurements for Single Point Incremental Forming: An Experimental Study, Advanced Materials Research, 6-8, 441-448, 2005 .

[8] Dzitac, I.; Filip, F.G.; Manolescu, M.J. (2017); Fuzzy logic is not fuzzy: World-renowned computer scientist Lotfi A. Zadeh, International Journal of Computers Communications \& Control, 12(6), 748-789, 2017.

[9] Dzitac, I. (2015); The fuzzification of classical structures: A general view, International Journal of Computers Communications \& Control, 10(6), 772-788, 2015.

[10] Gatea, S.; Ou, H.; Mccartney, G. (2016); Review on the influence of process parameters in incremental sheet forming, International Journal of Advanced Manufacturing Technology, 87, 479-499, 2016.

[11] Haidegger, T.; Kovacs, L.; Precup, R.-E.; Benyo, B.; Benyo, Z.; Preitl, S. (2012); Simulation and control for telerobots in space medicine, Acta Astronautica, 181(1), 390-402, 2012.

[12] Herrera-Viedma, E.; Lopez-Herrera, A.G. (2010); A review on information accessing systems based on fuzzy linguistic modelling, International Journal of Computational Intelligence Systems, 3(4), 420-437, 2010.

[13] Hyacinth Suganthi, X.; Natarajan, U.; Sathiyamurthy, S.; Chidambaram, K. (2013); Prediction of quality responses in micro-EDM process using an adaptive neuro-fuzzy inference system (ANFIS) model, International Journal of Advanced Manufacturing Technology, 68, 339-347, 2013.

[14] Jeswiet, J.; Micari, F.; Hirt, G.; Bramley A.; Duflou, J.; Allwood, J.(2005); Asymmetric Single Point Incremental Forming of Sheet Metal, Annals of CIRP, 54, 623-650, 2005.

[15] Jiao, Y.; Lei, S.; Pei, Z.J.; Lee, E.S. (2004); Fuzzy adaptive networks in machining process modeling: surface roughness prediction for turning operations, International Journal of Machine Tools and Manufacture, 44(15), 1643-1651, 2004.

[16] Kumanan, S.; Jesuthanam, C. P. (2008); Ashok Kumar, R.; Application of multiple regression and adaptive neuro fuzzy inference system for the prediction of surface roughness, International Journal of Advanced Manufacturing Technology, 35, 778-788, 2008.

[17] Li, Y.; Liu, Z.; Lu, H.; Daniel, W. J. T.; Liu, S.; Meehan, P. A. (2014); Efficient force prediction for incremental sheet forming and experimental validation, International Journal of Advanced Manufacturing Technology, 73, 571-587, 2014.

[18] Micari, F.; Ambrogio, G.; Filice, L. (2007); Shape and dimensional accuracy in single point incremental forming: State of the art and future trends, Journal of Materials Processing Technology, 191(1-3), 390-395, 2007.

[19] Oprea, M.; Mihalache, S. F.; Popescu, M. (2017); Computational Intelligence-based PM2.5 Air Pollution Forecasting, International Journal of Computers Communications \& Control, 12(3), 365-380, 2017. 
[20] Perez-Santiago, R.; Bagudanch Frigolă ̌̌and I.; Garcia-Romeu de Luna, M.L. (2011); Force Modeling in Single Point Incremental Forming of Variable Wall Angle Components, Key Engineering Materials, 473, 833-840, 2011.

[21] Precup, R.-E.; Hellendoorn, H. (2011); A survey on industrial applications of fuzzy control, Computers in Industry, 62, 213-226, 2011.

[22] Salahshoor, K.; Kordestani, M.; Khoshro, M.S. (2010); XFault detection and diagnosis of an industrial steam turbine using fusion of SVM (support vector machine) and ANFIS (adaptive neuro-fuzzy inference system) classifiers, Energy, 35, 5472-5482, 2010.

[23] Schafer, T.; Schraft, R.D. (2005); Incremental sheet metal forming by industrial robots, Rapid Prototyping Journal, 11(5), 278-286, 2005.

[24] Tera, M.; Breaz, R.E.; Bologa, O.; Racz, S.G.(2015); Developing a Knowledge Base about the Technological Forces within the Asymmetric Incremental Forming Process, Key Engineering Materials, 651, 1115-1121, 2015.

[25] Tseng, T.-L.; Konada, U.; Kwon, Y. (2016); A novel approach to predict surface roughness in machining operations using fuzzy set theory, Journal of Computational Design and Engineering, 3, 1-13, 2016.

[26] Velosa De Sena, J.I. (2015); Advanced numerical framework to simulate Incremental Forming Processes, Ph.D. Thesis, University of Aveiro, Portugal, 2015. 